\title{
Rectal cancer treatment and outcomes in elderly patients treated with curative intent
}

\author{
SHARLYN KANG ${ }^{1,2}$, KATE J. WILKINSON ${ }^{3,4}$, DANIEL BRUNGS ${ }^{1,2}$, WEI CHUA ${ }^{3-5}$, WENG NG $^{3-5}$ JAMES CHEN $^{1}$, \\ ELIAS NASSER ${ }^{1}$, MARK LEE $^{4}$, KAREN WONG $^{4,5}$, LES BOKEY $^{3,5,6}$, ROBERT WINN $^{7}$, \\ SONI PUTNIS ${ }^{7}$, CHEOK SOON LEE $^{3,5,8}$ and STEPHANIE HUI-SU LIM ${ }^{3,5,9}$ \\ ${ }^{1}$ Illawarra Cancer Care Centre; ${ }^{2}$ Illawarra Health and Medical Research Institute, University of Wollongong, \\ Wollongong, New South Wales 2500; ${ }^{3}$ Western Sydney University, Campbelltown, New South Wales 2560; \\ ${ }^{4}$ Liverpool Cancer Therapy Centre; ${ }^{5}$ Medical Oncology Group, Ingham Institute for Applied Medical Research; \\ ${ }^{6}$ Colorectal Unit, Division of Surgery, Liverpool Hospital, Liverpool, New South Wales 2170; \\ ${ }^{7}$ Colorectal Unit, Division of Surgery, Wollongong Hospital, Wollongong, New South Wales 2500; \\ ${ }^{8}$ Department of Anatomical Pathology, Liverpool Hospital, Liverpool, New South Wales 2170; \\ ${ }^{9}$ Macarthur Cancer Therapy Centre, Campbelltown, New South Wales 2560, Australia
}

Received March 31, 2021; Accepted July 9, 2021

DOI: $10.3892 / \operatorname{mco} .2021 .2418$

\begin{abstract}
The elderly population comprises a significant proportion of patients diagnosed with rectal cancer. However, there is a lack of evidence to guide treatment decisions in this group. Thus, this multicentre study compares the histopathology, treatment patterns and outcomes between the elderly and young populations with non-metastatic rectal cancer. The present study reported on the clinicopathological variables, treatment modalities and survival outcomes in 736 patients diagnosed with non-metastatic rectal cancer between 2006 and 2015. Patients were divided into the following two groups, $<70$ and $\geq 70$ years of age, which were compared using Chi-square and survival outcome analysis using Kaplan-Meier. Elderly patients made up nearly half of the cohort and were less likely to undergo trimodality therapy or be discussed in a multidisciplinary meeting. Surgery in the elderly patients was associated with increased mortality. Elderly patients had worse cancer-specific survival (75 vs. 85\%), which was particularly evident in stage III disease (hazard ratio, 2.1). Elderly patients in this subgroup treated with trimodality therapy had similar survival outcomes to younger patients. Elderly patients with locally advanced rectal cancer comprise a large proportion of the patient cohort. Consideration should be given for trimodality therapy in this group, taking into account biological age, especially in the context of increasing
\end{abstract}

Correspondence to: Dr Stephanie Hui-Su Lim, Medical Oncology Group, Ingham Institute for Applied Medical Research, 1 Campbell Street, Liverpool, New South Wales 2170, Australia

E-mail: stephanie.lim@health.nsw.gov.au

Key words: rectal cancer, elderly patients, outcomes, geriatric oncology, chemoradiation life expectancy and improvement in the management of age-related comorbidities.

\section{Introduction}

Colorectal cancer is the third and second most common cancer in males and females respectively (1). Rectal cancers comprise a third of colorectal cancer cases and more commonly affects the elderly with a peak incidence at 80-84 years (2).

Management of non-metastatic, locally advanced rectal cancer is challenging and requires multidisciplinary care. Elderly patients are at risk of aged-based disparities in cancer treatment, which may include being under-treated due to their chronological age, or over-treated for their degree of frailty (3). It is often challenging for the treating physician to find the optimal balance between attaining good disease control and limiting the toxicities of treatment for the elderly patient who may also have competing comorbidities. Data to guide treatment of elderly patients with rectal cancer is limited as the elderly patients are often under-represented in prospective clinical trials (4). The optimal treatment approach in this group will likely become even more nuanced with the gradual paradigm shift toward non-operative approaches in locally advanced rectal cancer (5).

The current standard surgical management of rectal cancer involves performing a total mesorectal excision (TME) for improved local control of disease and survival $(6,7)$. Other operative approaches for selected patients with low risk early rectal cancers include transanal endoscopic microsurgery (TEM) and local excision $(8,9)$. For locally advanced rectal cancer (clinical $\geq \mathrm{T} 3$ or node positive), trimodality therapy consisting of neoadjuvant chemoradiotherapy followed with surgery, with adjuvant post-operative chemotherapy, is the current standard of care (10). Trimodality therapy has been shown to have a survival benefit in elderly patients. Cancer specific survival 
was shown to be $70 \%$ in patients aged $>75$ who received neoadjuvant therapy, compared to $52 \%$ with surgery alone and $60 \%$ with adjuvant therapy (11). Multiple studies have found that older patients are less likely to receive neoadjuvant therapy, and that this is associated with poorer cancer-specific survival (12-14). One study found that each 5 years over the age of 70 was associated with a $37 \%$ increase in cancer-related mortality (13).

The reasons for a lower uptake of trimodality therapy in the older patients is multifactorial, including an increased incidence of treatment-related complications. The literature is divided on this, with some studies demonstrating an increase in complication rates (15-17), and some reporting a good tolerance of treatment (18-20).

Taking the evidence into account, the literature suggests that selected elderly patients should be treated in the same way, if comorbidity allows (21-23). The likelihood of initiation of therapy was found to be $22 \%$ lower in elderly patients, even after adjusting for comorbidities and other variables (24).

There is also data to suggest that elderly patients may have a different biology to younger patients. Patients over the age of 75 were found to have a lower likelihood of having distant metastases (12) and less advanced stage at presentation (13).

Given the lack of clarity in the literature, we aimed to examine the treatment patterns and outcomes of the elderly population with non-metastatic rectal cancer.

\section{Materials and methods}

Study population. The study received approval from the South Western Sydney Local Health District and the Illawarra Shoalhaven Local Health District ethics committees. The study was performed in accordance with the Declaration of Helsinki. The need for informed consent was waived due to the low and negligible risk, and retrospective nature, of the work.

We utilised data from prospectively collated electronic records to identify patients with a histological diagnosis of rectal adenocarcinoma from 2006-2015, treated in the South Western Sydney and Illawarra Shoalhaven Local Health Districts, Australia. Patients with metastatic disease at diagnosis were excluded. Stage of disease was based on the 8th edition of the American Joint Committee on Cancer and College of American Joint Pathologists (AJCC) (25). Staging was based on clinical stage in patients undergoing neoadjuvant therapy, or pathological stage for patients who had surgery upfront. Clinicopathological variables, treatment modalities, recurrence and survival data were analysed.

Relapse-free survival was defined as the date of diagnosis to recurrence locally or distantly. Cancer specific survival was defined as date of diagnosis to death from rectal cancer. Overall survival was defined as the date of diagnosis to death from any cause. Patients who had not recurred and are still alive were censored at the date of last follow up.

Statistical analysis. Clinicopathological factors and treatment utilisation rates between patients $<70$ and $\geq 70$ years were compared using Chi-Square. Median values for survival and corresponding 95\% confidence intervals (CI) were calculated using Kaplan-Meier methods, and the log rank test was used to calculate P-values. Unadjusted and multivariable Cox proportional hazards regression analyses were used to estimate the association of age with survival outcomes, and to calculate corresponding hazard ratios (HRs) and 95\% confidence intervals. The following variables were included in the multivariate model: Age, grade, lymphovascular invasion, perineural invasion, TNM stage, and receipt of adjuvant treatment. All statistical analyses were performed using SAS 9.2 software (SAS Institute, Inc.).

\section{Results}

Clinicopathological variables. We identified 736 patients with localized (stage I-III) rectal cancer, with median follow-up of 3.4 years. Of these, $326(44.2 \%)$ were $\geq 70$ years (median age at diagnosis 67 years, range 21-94). Elderly patients were more likely to present with earlier stage disease (stage III 47.6 vs. $57.1 \%, \mathrm{P}=0.03$ ), but there were no differences in other histopathological variables with age (Table I).

Treatment modalities. Elderly patients were more likely to be treated with a non-operative approach across all stages (7.4 vs. $2.0 \%, \mathrm{P}=0.0014$ ). In the management of stage I rectal cancer, a small percentage of elderly patients were treated non-operatively whilst all patients $<70$ years had curative intent surgery $(8.8$ vs. $0 \%, \mathrm{P}=0.0079)$. In patients with stage III disease, elderly patients were more likely to be treated with surgery alone $(25.2$ vs. $4.3 \%, \mathrm{P}<0.001)$, less likely to receive neoadjuvant (36.8 vs. $54.3 \%, \mathrm{P}=0.007)$ or adjuvant therapy (47.1 vs. $79.1 \%, \mathrm{P}<0.001)$. These results are shown in Table II. Two hundred and eight patients received neoadjuvant chemoradiotherapy and only $4(2 \%)$ patients did not complete the entire radiotherapy course. Of these, 3 patients were $<70$ years and 1 patient was $\geq 70$ years.

Surgical modality also differed with age, with the elderly patients less likely to undergo anterior resection and more likely to have a Hartmann's procedure $(\mathrm{P}<0.0001)$. The elderly cohort were also more likely to die within 30 days of surgery $(\mathrm{P}=0.0014)$ and less likely to be discussed at a multidisciplinary meeting $(\mathrm{P}=0.01)$, as depicted in Table $\mathrm{I}$. The majority of post-operative deaths were from emergency surgeries for acute presentations such as bowel perforation.

Relapse and survival data. Overall survival was poorer in the elderly cohort (5 year overall survival 52 vs. 82\%, P<0.0001), Fig. 1A. Univariate analyses for overall survival showed age, grade, presence of lymphovascular or perineural invasion, stage and adjuvant therapy to be significant predictors (Table III). Age, tumour grade, perineural invasion and adjuvant treatment remained significant in multivariate analyses.

Cancer specific survival was also poorer in the elderly cohort (5 year cancer specific survival 75 vs. $85 \%, \mathrm{P}=0.008$ ), Fig. 1B. For cancer-specific survival, age and histopathological variables were significant, but treatment modality did not impact outcomes in multivariate analysis (Table III).

Relapse-free survival was affected significantly by grade, lymphovascular and perineural invasion, as well as stage 
Table I. Clinicopathological characteristics, surgical management and outcomes stratified by age.

\begin{tabular}{|c|c|c|c|c|}
\hline \multirow[b]{2}{*}{ Clinicopathological characteristics } & \multicolumn{2}{|c|}{ Age, years, n (\%) } & \multirow[b]{2}{*}{ Total, n (\%) } & \multirow[b]{2}{*}{ P-value } \\
\hline & $<70$ & $\geq 70$ & & \\
\hline Total & $410(66.0)$ & $326(44.0)$ & $736(100.0)$ & \\
\hline Sex, male & $269(65.6)$ & $202(62.0)$ & $471(64.0)$ & 0.3000 \\
\hline \multicolumn{5}{|l|}{ TNM stage } \\
\hline I & $77(18.8)$ & $80(24.5)$ & $157(21.3)$ & \multirow[t]{3}{*}{0.0300} \\
\hline II & $99(24.1)$ & $91(27.9)$ & $190(25.8)$ & \\
\hline III & $234(57.1)$ & $155(47.6)$ & $389(52.9)$ & \\
\hline Lymphovascular invasion $^{\mathrm{a}}$ & $82(20.8)$ & $62(21.3)$ & $144(21.1)$ & 0.8700 \\
\hline Perineural invasion ${ }^{\mathrm{b}}$ & $50(13.2)$ & $30(10.8)$ & $80(12.2)$ & 0.3700 \\
\hline Positive margin ${ }^{c}$ & $21(5.3)$ & $16(5.5)$ & $37(5.4)$ & 0.3900 \\
\hline Grade $3^{\mathrm{d}}$ & $37(9.2)$ & $28(9.2)$ & $65(9.2)$ & 0.9800 \\
\hline Discussed at MDT & $222(59.5)$ & $155(50.2)$ & $377(55.3)$ & 0.0100 \\
\hline \multicolumn{5}{|l|}{ Surgery ${ }^{\mathrm{e}}$} \\
\hline Anterior resection & $271(66.6)$ & $175(54.2)$ & $446(61.1)$ & \multirow[t]{5}{*}{$<0.0001$} \\
\hline APR & $93(23.9)$ & $81(25.1)$ & $174(23.8)$ & \\
\hline Hartmann's procedure & $6(1.5)$ & $19(5.9)$ & $25(3.4)$ & \\
\hline Local Resection & $9(2.2)$ & $21(6.5)$ & $30(4.1)$ & \\
\hline Other, including palliative surgery & $20(4.9)$ & $3(0.9)$ & $23(3.1)$ & \\
\hline No surgery & $8(2.0)$ & $24(7.4)$ & $32(4.4)$ & 0.0014 \\
\hline Death within 30 days of surgery & $0(0.0)$ & $8(2.5)$ & $8(1.1)$ & 0.0014 \\
\hline
\end{tabular}

a52 patients missing; b80 patients missing; ${ }^{5} 52$ patients missing; ${ }^{\text {d32 }} 2$ patients missing; ${ }^{\mathrm{e}}$ six patients missing; APR, abdominoperineal resection; MDT, multidisciplinary meeting; TNM, tumour/node/metastasis staging.
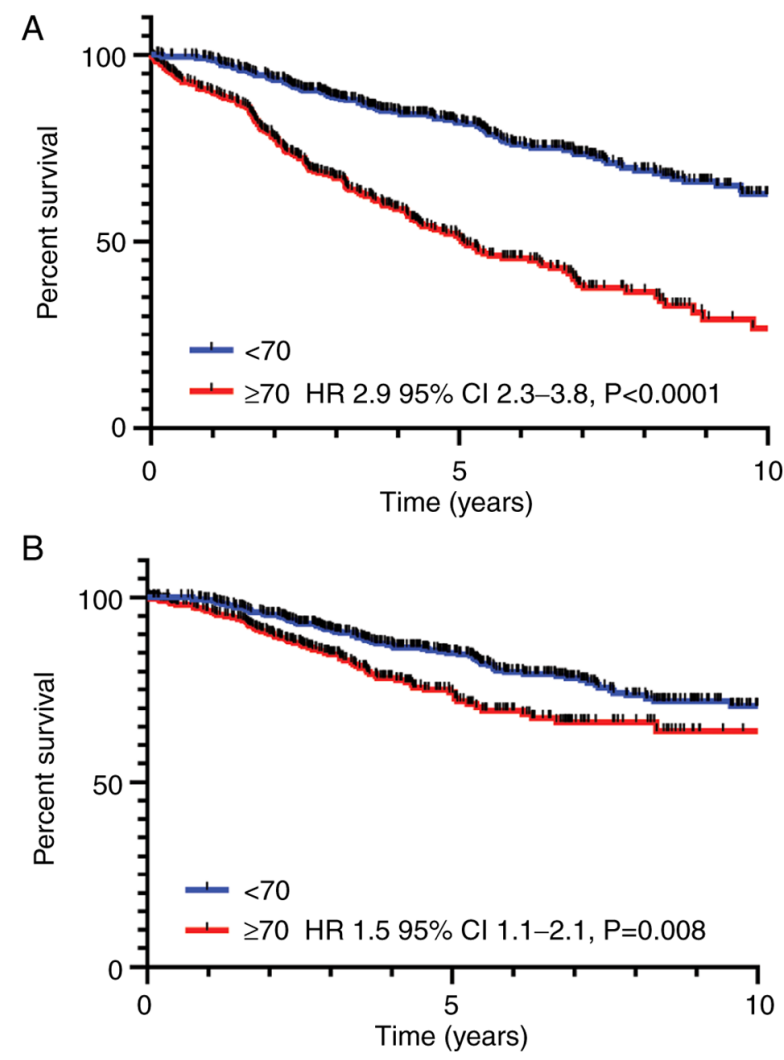

Figure 1. (A) Kaplan-Meier analysis for overall survival in patients $\geq 70$ $(n=326)$ vs. $<70$ years $(n=410)$ of age. (B) Kaplan-Meier analysis for cancer-specific survival in patients $\geq 70(n=326)$ vs. $<70$ years $(n=410)$ of age. HR, hazard ratio; CI, confidence internal.
(Table IV). Use of neoadjuvant and adjuvant therapy predicted for worse survival in univariate analyses but were not significant in multivariate analyses.

Cancer-specific survival stratified by age. Elderly patients with stage III disease have worse outcomes compared to younger patients (Table V). However, elderly patients who received neoadjuvant $+/$ - adjuvant therapy did not have significantly different outcomes compared to younger patients.

Summary of salient findings. Elderly patients composed almost half of the cohort, and presented with earlier stage disease. They were less likely to undergo trimodality therapy or discussed in a multidisciplinary meeting. Surgery in the elderly patients was more commonly a Hartmann's procedure, and surgery was associated with increased immediate post-operative mortality. Elderly patients had worse overall survival and cancer-specific survival, particularly evident in stage III disease. Elderly patients in this subgroup treated with trimodality therapy had similar survival outcomes to younger patients.

\section{Discussion}

Our study found that almost half of patients with non-metastatic rectal cancer undergoing treatment were over the age of 70 . Although the majority $(>90 \%)$ of elderly rectal cancer patients were treated with curative intent, this was significantly less than in younger patients. Elderly patients were 
Table II. Treatment modalities stratified by stage.

A, Stage I $(n=157)$

\begin{tabular}{|c|c|c|c|}
\hline \multirow[b]{2}{*}{ Treatment modalities } & \multicolumn{2}{|c|}{ Age, years } & \multirow[b]{2}{*}{ P-value } \\
\hline & $<70$ & $\geq 70$ & \\
\hline Total & 77 & 80 & \\
\hline Non-operative approach & 0 & 7 & \\
\hline Curative resection & 77 & 73 & 0.0079 \\
\hline Surgery only & 74 & 70 & 0.0510 \\
\hline Neoadjuvant therapy & 3 & 1 & 0.2900 \\
\hline Adjuvant therapy & 2 & 2 & 0.9600 \\
\hline
\end{tabular}

B, Stage II $(\mathrm{n}=190)$

\begin{tabular}{|c|c|c|c|}
\hline \multirow[b]{2}{*}{ Treatment modalities } & \multicolumn{2}{|c|}{ Age, years } & \multirow[b]{2}{*}{ P-value } \\
\hline & $<70$ & $\geq 70$ & \\
\hline Total & 99 & 91 & \\
\hline Non-operative approach & 5 & 7 & \\
\hline Curative resection & 94 & 84 & 0.4500 \\
\hline Surgery only & 29 & 59 & $<0.0001$ \\
\hline Neoadjuvant therapy & 52 & 22 & $<0.0001$ \\
\hline Adjuvant therapy & 34 & 10 & 0.0001 \\
\hline
\end{tabular}

C, Stage III $(n=389)$

\begin{tabular}{|c|c|c|c|}
\hline \multirow[b]{2}{*}{ Treatment modalities } & \multicolumn{2}{|c|}{ Age, years } & \multirow[b]{2}{*}{ P-value } \\
\hline & $<70$ & $\geq 70$ & \\
\hline Total & 234 & 155 & \\
\hline Non-operative approach & 5 & 16 & \\
\hline Curative resection & 229 & 139 & 0.0005 \\
\hline Surgery only & 10 & 39 & $<0.0010$ \\
\hline Neoadjuvant therapy & 127 & 57 & 0.0070 \\
\hline Adjuvant therapy & 185 & 73 & $<0.0010$ \\
\hline
\end{tabular}

less likely to receive trimodality therapy or be discussed in a multidisciplinary meeting. The more conservative approach toward treatment in the elderly may be largely due to the uncertainty around clinical decision making in this group, as they are largely excluded from clinical trials. In addition, the elderly have competing comorbidities which may complicate treatment. The elderly group was also less likely to undergo an anterior resection, and more likely to undergo a Hartmann's procedure or abdominoperineal resection. Surgery was associated with a higher death rate within 30 days post-operatively, albeit rates are still low (2.5\%) with most of these being emergency surgeries for acute presentations such as bowel perforation.

In this study, the overall survival and cancer specific survival for elderly patients with non-metastatic rectal cancer was significantly worse compared to younger patients. In stage III patients, we found that cancer-specific outcomes were more than two times poorer compared to younger patients. However, in the subgroup treated with trimodality therapy, outcomes were not inferior to the younger patients. These findings are consistent with previous studies in the literature which have reported lower utilisation of trimodality therapy in the elderly patients (12-14). The literature also reports inferior cancer specific outcomes in the older population $(11,13)$. However we did not find significant differences in recurrence rates in the elderly patients, suggesting that cancer specific survival may potentially be impacted by variable treatment modalities at the time of recurrence, or alternatively differences in surveillance post curative intent therapy.

The elderly population in our study presented with earlier stage disease which may reflect a difference in tumour biology 
Table III. Univariate and multivariate analyses for overall survival and cancer-specific survival.

A, Overall survival

\begin{tabular}{|c|c|c|c|c|}
\hline Clinicopathological characteristics & $\begin{array}{l}\text { Univariate HR } \\
\qquad(95 \% \mathrm{CI})\end{array}$ & P-value & $\begin{array}{l}\text { Multivariate HR } \\
\qquad(95 \% \mathrm{CI})\end{array}$ & P-value \\
\hline Age $<70$, years & 1.0 & & & \\
\hline Age $\geq 70$, years & $2.9(2.3-3.8)$ & $<0.0001$ & $2.6(2.0-3.5)$ & $<0.0001$ \\
\hline Grade 1-2 & 1.0 & & & \\
\hline Grade 3 & $1.8(1.3-2.6)$ & 0.0010 & $1.5(1.0-2.2)$ & 0.0420 \\
\hline Lymphovascular invasion & $1.6(1.2-2.1)$ & 0.0040 & $1.3(0.9-1.8)$ & 0.1600 \\
\hline Perineural invasion & $2.1(1.5-2.8)$ & $<0.0001$ & $2.2(1.6-3.2)$ & $<0.0001$ \\
\hline \multicolumn{5}{|l|}{ TNM stage } \\
\hline I & 1.0 & 0.0500 & 1.0 & 0.2800 \\
\hline II & $1.5(1.1-2.2)$ & & $1.4(0.9-2.1)$ & \\
\hline III & $1.2(0.9-1.7)$ & & $1.4(0.9-2.2)$ & \\
\hline Adjuvant treatment & $0.6(0.4-0.7)$ & $<0.0001$ & $0.6(0.5-0.9)$ & 0.0045 \\
\hline Neoadjuvant treatment & $0.9(0.7-1.1)$ & 0.3600 & $1.0(0.8-1.4)$ & 0.9600 \\
\hline
\end{tabular}

B, Cancer-specific survival

\begin{tabular}{lccc}
\hline Clinicopathological characteristics & $\begin{array}{c}\text { Univariate HR } \\
(95 \% \mathrm{CI})\end{array}$ & $\begin{array}{c}\text { Multivariate HR } \\
(95 \% \text { CI })\end{array}$ & $\begin{array}{c}\text { P-value } \\
\text { Age } \geq 70, \text { years }\end{array}$ \\
Grade 3 & $1.5(1.1-2.1)$ & 0.0080 & 0.0400 \\
Lymphovascular invasion & $2.8(1.8-4.2)$ & $<0.0001$ & $2.1(1.4-3.4)$ \\
Perineural invasion & $2.1(1.5-3.2)$ & $<0.0001$ & $1.5(1.0-2.3)$ \\
TNM stage & $2.6(1.7-3.9)$ & $<0.0001$ & $1.9(1.2-2.9)$ \\
I & & & 0.0400 \\
II & 1.0 & $<0.0001$ & 0.0040 \\
III & $7.3(3.1-17.1)$ & & $6.2(2.2-17.7)$ \\
Adjuvant treatment & $7.2(3.1-16.3)$ & & $0.7(2.3-19.6)$ \\
Neoadjuvant treatment & $1.04(0.8-1.4)$ & 0.8000 & $0.8(0.5-1.2)$ \\
\hline
\end{tabular}

HR, hazard ratio; CI, confidence interval; TNM, tumour/node/metastasis staging.

Table IV. Univariate and multivariate analyses for relapse-free survival.

\begin{tabular}{|c|c|c|c|c|}
\hline Clinicopathological characteristics & $\begin{array}{c}\text { Univariate HR } \\
(95 \% \mathrm{CI})\end{array}$ & P-value & $\begin{array}{c}\text { Multivariate HR } \\
(95 \% \mathrm{CI})\end{array}$ & $\mathrm{P}$-value \\
\hline Age $\geq 70$ & $0.9(0.7-1.2)$ & 0.5000 & $1.0(0.7-1.3)$ & 0.9900 \\
\hline Grade 3 & $2.1(1.5-3.2)$ & $<0.0001$ & $1.9(1.2-2.8)$ & 0.0030 \\
\hline Lymphovascular invasion & $1.9(1.4-2.5)$ & $<0.0001$ & $1.4(1.0-2.0)$ & 0.0400 \\
\hline Perineural invasion & $2.2(1.5-3.1)$ & $<0.0001$ & $1.7(1.1-2.4)$ & 0.0108 \\
\hline \multicolumn{5}{|l|}{ TNM stage } \\
\hline I & 1.0 & $<0.0001$ & 1.0 & 0.0030 \\
\hline II & $3.4(2.0-5.8)$ & & $2.9(1.6-5.5)$ & \\
\hline III & $3.8(2.3-6.2)$ & & $2.7(1.4-5.1)$ & \\
\hline Adjuvant treatment & $1.5(1.2-2.0)$ & 0.0030 & $1.1(0.8-1.6)$ & 0.6000 \\
\hline Neoadjuvant treatment & $1.5(1.2-2.0)$ & 0.0030 & $1.2(0.9-1.6)$ & 0.4000 \\
\hline
\end{tabular}

HR, hazard ratio; CI, confidence interval; TNM, tumour/node/metastasis staging. 
Table V. Univariate analyses of cancer-specific survival stratified by age.

\begin{tabular}{lcr}
\hline Stages & Univariate HR (95\% CI) & P-value \\
\hline Stage I & $0.8(0.1-4.5)$ & 0.8000 \\
Stage II & $1.1(0.6-1.9)$ & 0.8000 \\
Stage III & $2.1(1.4-3.2)$ & 0.0002 \\
Stages II/III and received neoadjuvant therapy $^{\mathrm{b}}$ & $1.4(0.8-2.4)$ & 0.2600 \\
Stages II/III and received neoadjuvant and adjuvant therapy $^{\mathrm{c}}$ & $1.4(0.7-3.2)$ & 0.3200
\end{tabular}

${ }^{a} \geq 70$ vs. $<70$ years; ${ }^{b} n=254$ (176 vs. 78$) ;{ }^{c} n=146$ (112 vs. 34$)$; HR, hazard ratio; CI, confidence interval.

or be attributed to incidental findings whilst screening for other conditions. This is consistent with some studies in the literature $(12,13)$. A study exploring the genomic makeup of colorectal tumours found that older patients, defined as $\geq 70$, had a greater index of genetic mutations, and a higher incidence of KRAS and BRAF mutations but less PTEN/PIK3CA mutations (26).

Limitations of this study include its retrospective nature, and the inability to assess the benefits of treatment due to selection bias. Fitter patients are expected to be selected to undergo adjuvant therapy thereby affecting overall survival, and patients with poor biology or very locally advanced disease are expected to undergo trimodality therapy hence translating to worse cancer specific outcomes. We recognise that we did not collect data on comorbidities and performance status which may impact on treatment pattern selection. Future research focused on the geriatric population will require information on comorbidities, nutritional status, cognitive status, and can employ the use of geriatric screening tools.

The toxicities and morbidity associated with trimodality therapy for locally advanced rectal cancer impact deliverability, especially in the elderly population. These patients are often excluded in clinical trial populations and hence the best management strategies and outcomes of treatment are unclear. There is also a shift towards a non-operative approach in the treatment of locally advanced rectal cancer (5), making treatment decision making in the older patients even more nuanced. Our study adds valuable insight into the treatment practices and outcomes in these patients, which comprise a large proportion of the patient population. Consideration should be given into deciding whether an 'elderly' patient should receive trimodality therapy, depending on their biological age and comorbidities, and not purely on chronological age alone. Elderly patients would benefit from being discussed in a multidisciplinary meeting. This is especially the case as life expectancy continues to rise, chronic illnesses are better managed, and definitions of the older patient are likely to shift upwards with time.

\section{Acknowledgements}

The authors would like to acknowledge Dr Sharlyn Kang (Illawarra Cancer Care Centre, University of Wollongong, Wollongong, New South Wales, Australia) for her contribution to the research in this manuscript before her passing and would like to dedicate this work to her memory. The abstract was presented in poster form at the American Society of Clinical Oncology (ASCO) Gastrointestinal Cancers Symposium January 2019 in San Francisco, CA and published as abstract no. 4 in Journal of Clinical Oncology Volume 37 (Suppl) (February 01, 2019) 678-678.

\section{Funding}

No funding was received.

\section{Availability of data and materials}

The datasets used and/or analyzed during the current study are available from the corresponding author on reasonable request.

\section{Authors' contributions}

SK, KJW, DB and SHSL designed and conceived the present study. SK, KJW, DB, WC, WN, JC, EN, ML, KW, LB, RW, SP, CSL and SHSL were all responsible for the provision of patient materials and data collection. SK, KJW, DB and SHSL performed data analysis and interpretation. SK, KJW and DB confirm the authenticity of all the raw data. All authors wrote the manuscript. All authors have read and approved the final manuscript.

\section{Ethics approval and consent to participate}

The present study was approved by the South Western Sydney Local Health District (approval no. HREC/12/LPOOL/102) and the ethics committee of the Illawarra Shoalhaven Local Health District (approval no. LNR/15/WGONG/61). This study was performed in accordance with the Declaration of Helsinki. The need for informed consent was waived due to the low and negligible risk, and retrospective nature of the work.

\section{Patient consent for publication}

Not applicable.

\section{Competing interests}

The authors declare that they have no competing interests. 


\section{References}

1. Ferlay J, Soerjomataram I, Dikshit R, Eser S, Mathers C, Rebelo M, Parkin DM, Forman D and Bray F: Cancer incidence and mortality worldwide: Sources, methods and major patterns in GLOBOCAN 2012. Int J Cancer 136: E359-E386, 2015.

2. Australian Institute of Health and Welfare 2015. Australia's Welfare 2015. Australia's welfare series no. 12. Cat. no. AUS 189. Canberra, 2015.

3. Lawler M, Selby P, Aapro MS and Duffy S: Ageism in cancer care. BMJ 348: g1614, 2014.

4. Hurria A, Dale W, Mooney M, Rowland JH, Ballman KV, Cohen HJ, Muss HB, Schilsky RL, Ferrell B, Extermann M, et al: Designing therapeutic clinical trials for older and frail adults with cancer: U13 conference recommendations. J Clin Oncol 32: 2587-2594, 2014

5. Greer JB and Hawkins AT: Non-operative management of rectal cancer. Semin Colon Rectal Surg 30: 79-84, 2019.

6. Heald RJ and Ryall RD: Recurrence and survival after total mesorectal excision for rectal cancer. Lancet 1: 1479-1482, 1986.

7. Kapiteijn E, Putter H and van de Velde CJ; Cooperative investigators of the Dutch ColoRectal Cancer Group: Impact of the introduction and training of total mesorectal excision on recurrence and survival in rectal cancer in The Netherlands. Br J Surg 89: 1142-1149, 2002.

8. Ahn T: What should be considered for local excision in early rectal cancer? Ann Coloproctol 35: 155-157, 2019.

9. Althumairi AA and Gearhart SL: Local excision for early rectal cancer: Transanal endoscopic microsurgery and beyond. J Gastrointest Oncol 6: 296-306, 2015.

10. Sauer R, Liersch T, Merkel S, Fietkau R, Hohenberger W, Hess C, Becker H, Raab HR, Villanueva MT, Witzigmann H, et al: Preoperative versus postoperative chemoradiotherapy for locally advanced rectal cancer: Results of the German CAO/ARO/AIO-94 randomized phase III trial after a median follow-up of 11 years. J Clin Oncol 30: 1926-1933, 2012.

11. Wan JF, Zhu J, Li GC, Sun WJ and Zhang Z: Implications for determining the optimal treatment for locally advanced rectal cancer in elderly patients aged 75 years and older. Oncotarget 6: 30377-30383, 2015.

12. Jung B, Pahlman L, Johansson R and Nilsson E: Rectal cancer treatment and outcome in the elderly: An audit based on the Swedish Rectal Cancer Registry 1995-2004. BMC Cancer 9: 68, 2009.

13. Chang GJ, Skibber JM, Feig BW and Rodriguez-Bigas M: Are we undertreating rectal cancer in the elderly? An epidemiologic study. Ann Surg 246: 215-221, 2007.

14. Thiels CA, Bergquist JR, Meyers AJ, Johnson CL, Behm KT, Hayman AV, Habermann EB, Larson DW and Mathis KL: Outcomes with multimodal therapy for elderly patients with rectal cancer. Br J Surg 103: e106-e114, 2016.

15. Shahir MA, Lemmens VE, van de Poll-Franse LV, Voogd AC, Martijn $\mathrm{H}$ and Janssen-Heijnen ML: Elderly patients with rectal cancer have a higher risk of treatment-related complications and a poorer prognosis than younger patients: A population-based study. Eur J Cancer 42: 3015-3021, 2006.
16. Margalit DN, Mamon HJ, Ancukiewicz M, Kobayashi W, Ryan DP, Blaszkowsky LS, Clark J, Willett CG and Hong TS: Tolerability of combined modality therapy for rectal cancer in elderly patients aged 75 years and older. Int J Radiat Oncol Biol Phys 81: e735-e741, 2011.

17. Francois E, Azria D, Gourgou-Bourgade S, Jarlier M, Martel-Laffay I, Hennequin C, Etienne PL, Vendrely V, Seitz JF, Conroy T, et al: Results in the elderly with locally advanced rectal cancer from the ACCOR12/PRODIGE 2 phase III trial: Tolerance and efficacy. Radiother Oncol 110: 144-149, 2014.

18. Choi Y, Kim JH, Kim JW, Kim JW, Lee KW, Oh HK, Kim DW, Kang SB, Song C and Kim JS: Preoperative chemoradiotherapy for elderly patients with locally advanced rectal cancer-a real-world outcome study. Jpn J Clin Oncol 46: 1108-1117, 2016.

19. Guimas V, Boustani J, Schipman B, Lescut N, Puyraveau M, Bosset JF and Servagi-Vernat S: Preoperative chemoradiotherapy for rectal cancer in patients aged 75 Years and older: Acute toxicity, compliance with treatment, and early results. Drugs Aging 33: 419-425, 2016.

20. Pasetto LM, Friso ML, Pucciarelli S, Basso U, Falci C, Bortolami A, Toppan P, Agostini M, Rugge M, Serpentini S, et al: Rectal cancer neoadjuvant treatment in elderly patients. Anticancer Res 26 (5B): 3913-3923, 2006.

21. Jiang DM, Raissouni S, Mercer J, Kumar A, Goodwin R, Heng DY, Tang PA, Doll C, MacLean A, Powell E, et al: Clinical outcomes of elderly patients receiving neoadjuvant chemoradiation for locally advanced rectal cancer. Ann Oncol 26: 2102-2106, 2015.

22. Tougeron D, Roullet B, Paillot B, Hamidou H, Tourani JM, Bensadoun RJ, Michel P and Silvain C: Safety and outcome of chemoradiotherapy in elderly patients with rectal cancer: Results from two French tertiary centres. Dig Liver Dis 44: 350-354, 2012.

23. Dobie SA, Warren JL, Matthews B, Schwartz D, Baldwin LM and Billingsley K: Survival benefits and trends in use of adjuvant therapy among elderly stage II and III rectal cancer patients in the general population. Cancer 112: 789-799, 2008.

24. Bohac GC, Guaqueta D, Cheng DM, Aschengrau A and Hartshorn KL: Disparity in the use of combined modality therapy for rectal cancer in the older adult. J Geriatr Oncol 4: 90-97, 2013.

25. Amin MB, Greene FL, Edge SB, Compton CC, Gershenwald JE, Brookland RK, Meyer L, Gress DM, Byrd DR and Winchester DP: The Eighth Edition AJCC cancer staging manual: Continuing to build a bridge from a population-based to a more 'personalized' approach to cancer staging. CA Cancer J Clin 67: 93-99, 2017.

26. Berg M, Danielsen SA, Ahlquist T, Merok MA, Agesen TH, Vatn MH, Mala T, Sjo OH, Bakka A, Moberg I, et al: DNA sequence profiles of the colorectal cancer critical gene set KRAS-BRAF-PIK3CA-PTEN-TP53 related to age at disease onset. PLoS One 5: e13978, 2010.

This work is licensed under a Creative Commons Attribution-NonCommercial-NoDerivatives 4.0 International (CC BY-NC-ND 4.0) License. 